\title{
Intractable hemorrhage from the site of bone marrow aspiration and trephine biopsy
}

Takeshi Iwasaki $^{1}$, Futoshi Iioka ${ }^{1 *}$, Takanori Taniguchi ${ }^{2}$, Hitoshi Ohno ${ }^{1}$

${ }^{1}$ Department of Hematology, Tenri Hospital; ${ }^{2}$ Department of Radiation, Tenri Hospital

Received 2017/10/13; accepted 2017/10/26; released online 2017/12/25

Keywords: bone marrow aspiration and trephine biopsy, hemorrhagic complication, hyperfibrinolytic state, acute myeloid leukemia

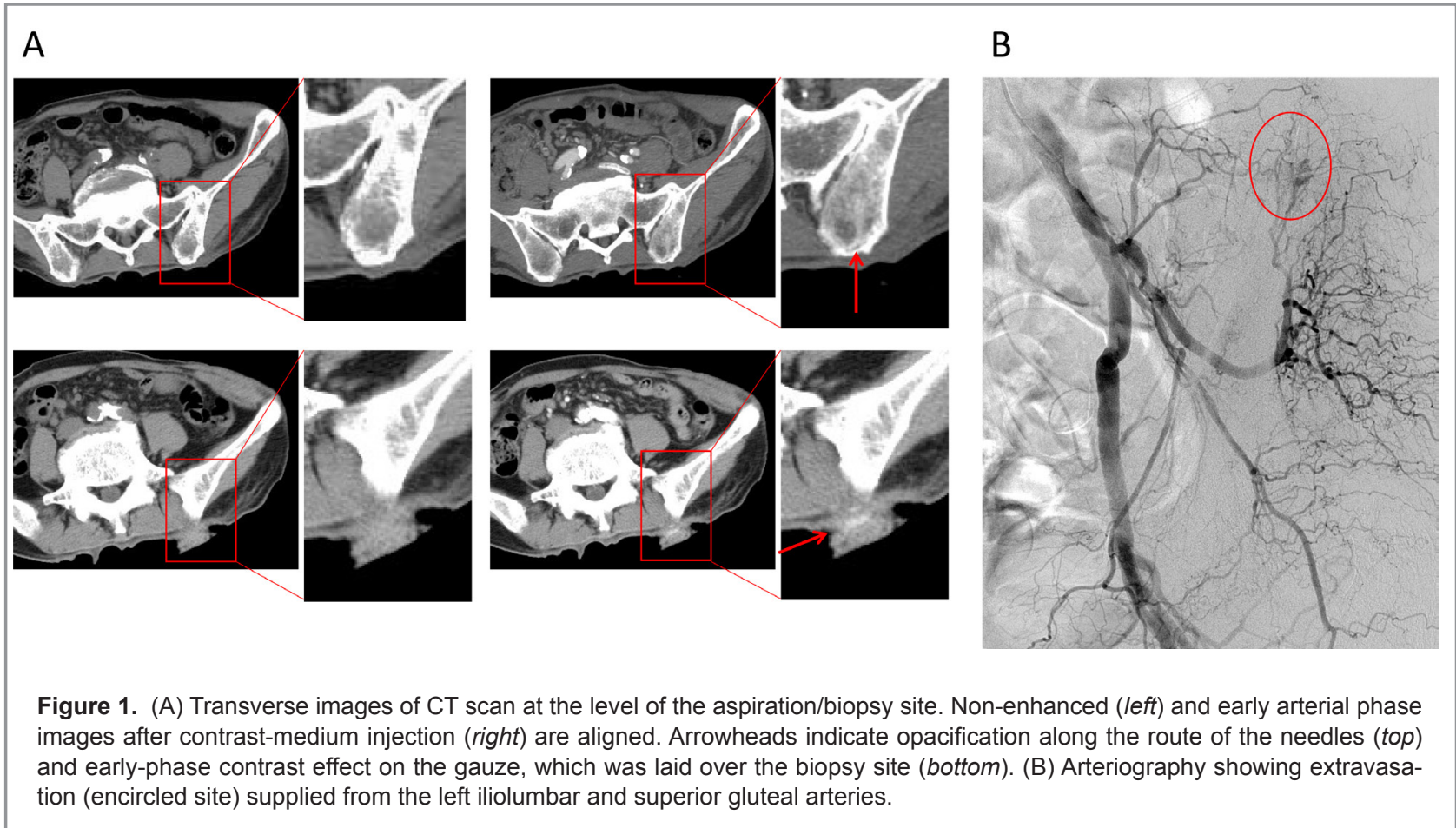

A 74-year-old man was admitted to our hospital for treatment of acute myeloid leukemia (AML). He had been treated for prodromal myelodysplastic syndrome with azacitidine; however, as the disease progressed into florid AML, intensive chemotherapy was considered. He had a medical history of myocardial infarction, requiring percutaneous coronary intervention and subsequent ad-

*Correspondence to: Futoshi Iioka, MD Department of Hematology, Tenri Hospital 200 Mishima, Tenri, Nara 632-8552, Japan e-mail: iioka@tenriyorozu.jp ministration of clopidogrel, right nephrectomy for renal tuberculosis, and left partial nephrectomy for renal cell carcinoma.

On the day of admission, bone marrow (BM) aspiration using a 15-gauge Illinois ${ }^{\mathrm{TM}}$ needle (\#DIN515X; Becton Dickinson Japan, Tokyo, Japan) and following trephine biopsy using an 8-gauge Jamshidi ${ }^{\mathrm{TM}}$ needle (\#DJ4008X; Becton Dickinson Japan) were performed from the left posterior superior iliac spine in the prone position under local anesthesia and sterile conditions. 

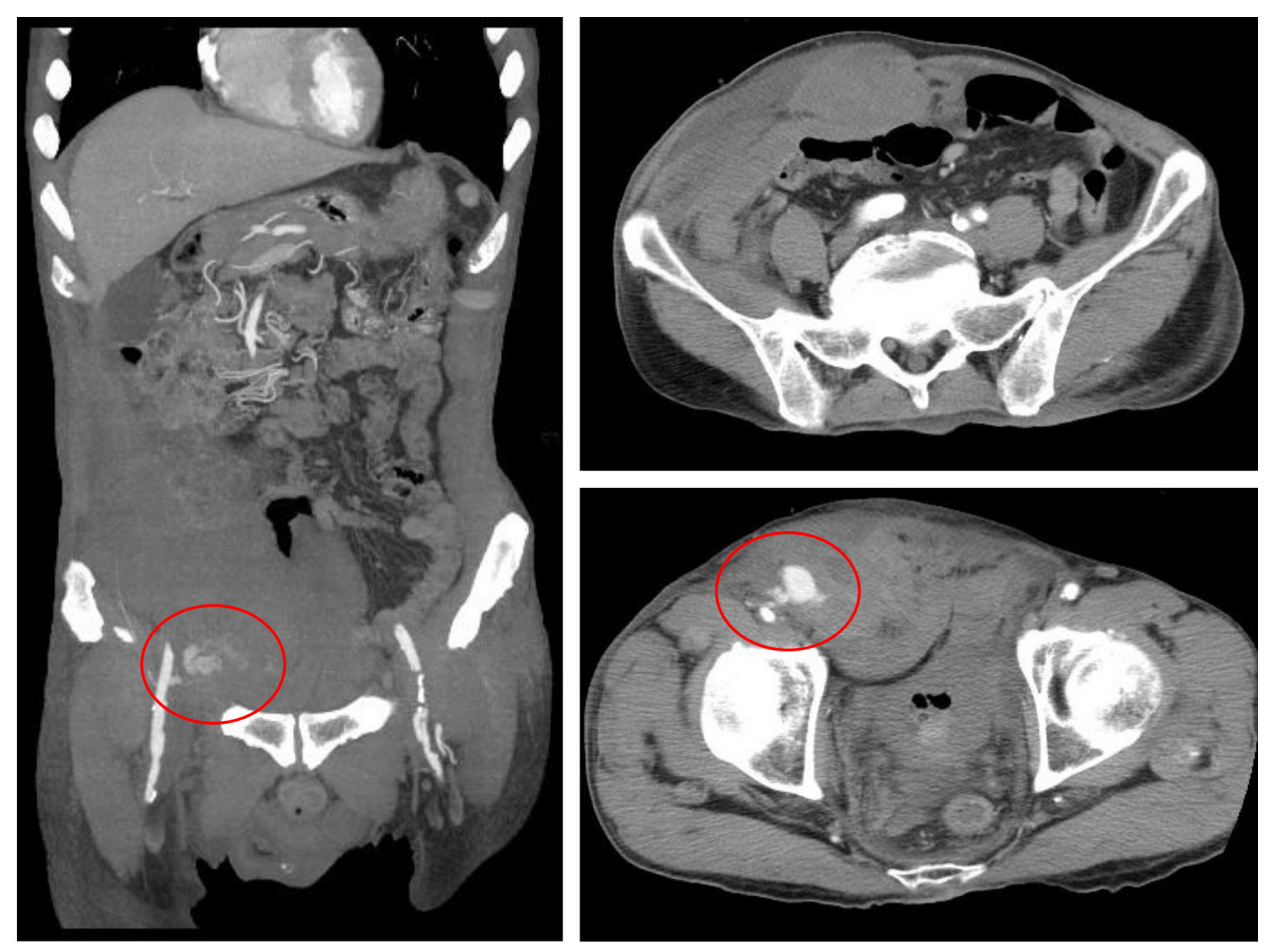

Figure 2. CT scan demonstrating marked hematoma extending from the right thigh to the abdominal wall after femoral artery catheterization. Coronal (left) and transverse (right) images are shown. Leakage of contrast materials from the puncture site is encircled.

The procedure was carried out by hematology department staff certified by the Japan Hematology Society. Immediately after the procedure, pressure was applied manually to the aspiration/biopsy site using sterile gauze until bleeding was not evident, and the patient was then moved into the supine position. Several hours later, the gauze was found to be contaminated with blood. Despite placing continuous pressure to the site, as well as transfusion with multiple units of fresh frozen plasma (FFP) and platelet concentrates (PC), bleeding persisted for the next two days.

Hematological and coagulation data obtained at the time of admission were: hemoglobin, $6.6 \mathrm{~g} / \mathrm{dL}$; white blood cell count, $26.47 \times 10^{3} / \mu \mathrm{L}$ with $53.5 \%$ leukemia blasts; platelet count, $66 \times 10^{3} / \mu \mathrm{L}$; prothrombin time, $16.6 \mathrm{sec}$; activated partial thrombin time, $37.6 \mathrm{sec}$; fibrinogen, $47 \mathrm{mg} / \mathrm{dL}$; antithrombin III, 83\%; fibrin degradation products (FDP), $144.8 \mu \mathrm{g} / \mathrm{mL}$ (reference, $<5 \mu \mathrm{g}$ /
$\mathrm{mL})$; D-dimer, $61.8 \mu \mathrm{g} / \mathrm{mL}(<1.0 \mu \mathrm{g} / \mathrm{mL})$; and soluble fibrin monomer complex, $22.4 \mu \mathrm{g} / \mathrm{mL}(<7 \mu \mathrm{g} / \mathrm{mL})$. Blood chemistry data were unremarkable except for albumin of $3.3 \mathrm{~g} / \mathrm{dL}$ and lactate dehydrogenase of $379 \mathrm{IU} / \mathrm{L}$. The BM demonstrated hypercellularity with $77.9 \%$ blasts and morphological features of multilineage dysplasia, fulfilling the diagnostic criteria for AML with myelodysplasia-related changes in the 2008 World Health Organization classification (Supplementary Figure S1).

On the $4^{\text {th }}$ hospital day, the bleeding became marked and pulsatile. A rod-shaped opacification area was found on computed tomography (CT) using contrast media during the arterial phase within the iliac crest corresponding to the route of the aspiration/biopsy needle, indicating that bleeding occurred within the BM space (Figure 1A ). Arterial angiography through the catheter placed in the left internal iliac artery revealed extravasation of contrast solution from the distal branches of 
the left iliolumbar and superior gluteal arteries at the position corresponding to the left posterior superior iliac spine (Figure 1B). Extravasating branches were then selected and occluded by gelatin sponge (Serescue ${ }^{\circledR}$; Astellas Pharma and Nippon Kayaku, Tokyo, Japan) until no signs of further extravasation were noted. The Angio-Seal devise (St. Jude Medical Japan, Tokyo, Japan) was applied to the puncture site of the femoral artery catheterization to assure hemostasis. Two days after the embolization, however, the patient developed marked hematoma caused by bleeding from the puncture site (Figure 2). Treatments and procedures performed over 4 weeks were: volume resuscitation for hypotension, narcotic analgesics given to relieve pain from the strain, ultrasound-guided manual compression of the bleeding site, administration of recombinant thrombomodulin $\alpha$ (Recomodulin; Asahi Kasei Pharma, Tokyo, Japan) and tranexamic acid, and transfusions of FFP and PC.

Six weeks after admission, we finally treated the patient with the ' $3+7$ ' induction chemotherapy for AML, reducing leukemia blasts and normalizing coagulation parameters (Supplementary Figure S2). However, he developed severe pneumonia and died on the $73^{\text {rd }}$ hospital day.

$\mathrm{BM}$ aspiration following biopsy from the iliac crest is routinely performed for the diagnosis of hematological disease, and complications associated with the procedure have been considered rare. The British Society of Hematology has published annual surveys on morbidities and mortalities associated with BM aspiration/ biopsy. ${ }^{1-4}$ According to the 2004 data published in 2006, $9(0.04 \%)$ hemorrhagic complications occurred among a total of 20,323 procedures. ${ }^{4}$ One of these patients exhibited laceration of a branch of the gluteal artery and required transfusion of red cells, fresh frozen plasma, and platelets together with embolization of the bleeding vessel. Another patient became hypotensive and was found to have developed a retroperitoneal hematoma from a damaged branch of the right internal iliac artery, requiring embolization. The most frequent risk factor for hemorrhagic complications was diagnosis of a myeloproliferative disorder or essential thrombocytosis. ${ }^{1-4}$

In contrast, there was no evidence that aspiration/ biopsy needles injured a pelvic artery in our patient; enhanced fibrinolytic activity associated with leukemia progression was likely the major cause of the intractable hemorrhage. The low-level of fibrinogen $(<100$ $\mathrm{mg} / \mathrm{dL})$, high-level of FDP $(>80 \mu \mathrm{g} / \mathrm{mL})$, and increase in FDP/D-dimer ratio (2.34) match the criteria for enhanced fibrinolysis-type of disseminated intravascular coagulopathy (DIC). ${ }^{5}$ This condition occurs in not only patients with acute promyelocytic leukemia (French-American-British M3) but also a fraction of patients with non-M3 AML; in a single-institution survey of 379 patients with non-M3 AML, 19 (5.0\%) presented with this type of DIC. ${ }^{6}$ Our current report indicates that hematologists must be aware that a hyperfibrinolytic state may lead to life-threatening hemorrhagic complications following aspiration and trephine biopsy of BM. We must assess the coagulation profiles associated with AML before the procedure to eliminate the risk of hemorrhage.

This case was presented at the monthly Grand Conference on February 9, 2017.

\section{REFERENCES}

1. Bain BJ. Bone marrow biopsy morbidity and mortality. $\mathrm{Br}$ J Haematol 2003;121:949-951.

2. Bain BJ. Bone marrow biopsy morbidity and mortality: 2002 data. Clin Lab Haematol 2004;26:315-318.

3. Bain BJ. Bone marrow biopsy morbidity: review of 2003. J Clin Pathol 2005;58:406-408.

4. Bain BJ. Morbidity associated with bone marrow aspiration and trephine biopsy - a review of UK data for 2004. Haematologica 2006;91:1293-1294.

5. Asakura H. Classifying types of disseminated intravascular coagulation: clinical and animal models. J Intensive Care 2014;2:20.

6. Weltermann A, Pabinger I, Geissler K, et al. Hypofibrinogenemia in non-M3 acute myeloid leukemia. Incidence, clinical and laboratory characteristics and prognosis. Leukemia 1998;12:1182-1186. 


\title{
骨髄穿刺・生検後の難治性出血
}

\author{
岩崎 毅 $^{1}$, 飯岡 大 $^{1}$, 谷口尚範 ${ }^{2}$, 大野仁嗣 ${ }^{1}$ \\ ${ }^{1}$ 天理よろづ相談所病院 血液内科 \\ ${ }^{2}$ 天理よろづ相談所病院 放射線部
}

\section{Supplementary Figures}

Figure S1. (A and B) Appearance of the BM aspirate smears, showing myeloblasts (arrows), immature monocytes (arrowheads), and mature neutrophils with abnormal nuclear segmentation and cytoplasmic hypo-granulation (asterisks) (Wright staining; original magnification, $\times 100$ objective lens). (C and D) BM core biopsy showing hypercellularity with predominantly immature cells. A subset of immature cells had irregular or folded nuclei, being morphologically consistent with monocytic precursors (H \& E staining; original magnification, $\times 4$ and $\times 100$, respectively).

Figure S2. Course of the treatment and laboratory parameters. The treatment for hemostasis included transfusions of fresh frozen products (FFP), recombinant thrombomodulin $\alpha(\mathrm{RT} \alpha)$, and tranexamic acid (TA). Induction chemotherapy consisted of $100 \mathrm{mg} / \mathrm{m}^{2}$ cytarabine on days 1 to 7 and $50 \mathrm{mg} / \mathrm{m}^{2}$ daunorubicin on days 1 to 3 . After the induction chemotherapy, coagulopathy was promptly resolved with reduction in leukemia blasts.

\section{Figure S1}

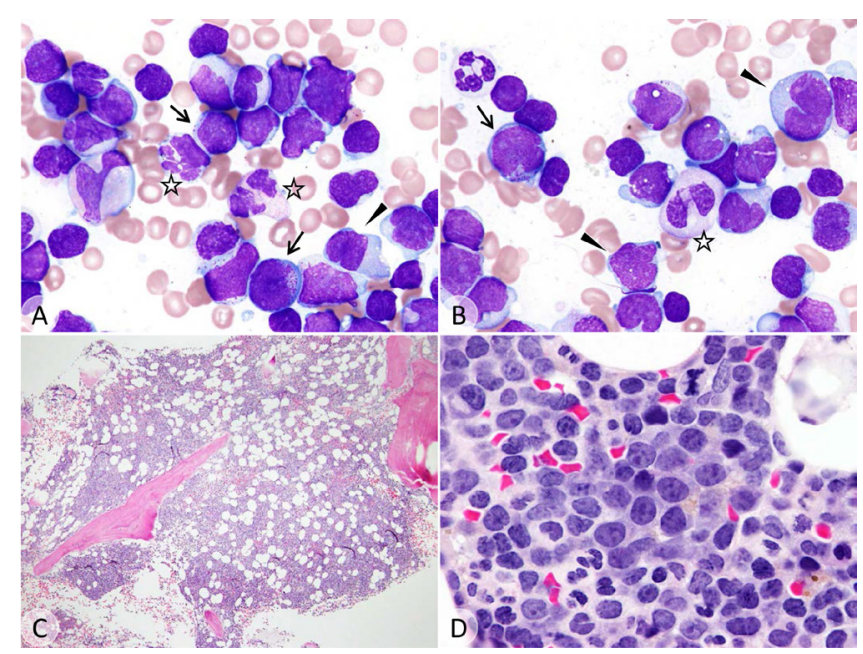

Figure S2

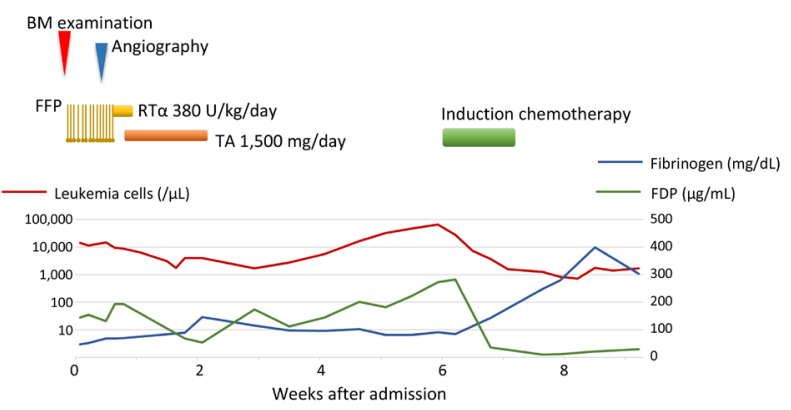

